Utah State University

DigitalCommons@USU

5-1977

\title{
Identification of Products Arising from the Metabolism of Cis-and Trans-Chlordane by Rat Liver Microsomes in Vitro: Outline of a Possible Metabolic Pathway
}

Alan Arthur Brimfield

Utah State University

Follow this and additional works at: https://digitalcommons.usu.edu/etd

Part of the Life Sciences Commons

\section{Recommended Citation}

Brimfield, Alan Arthur, "Identification of Products Arising from the Metabolism of Cis-and Trans-Chlordane by Rat Liver Microsomes in Vitro: Outline of a Possible Metabolic Pathway" (1977). All Graduate Theses and Dissertations. 3286.

https://digitalcommons.usu.edu/etd/3286

This Thesis is brought to you for free and open access by the Graduate Studies at DigitalCommons@USU. It has been accepted for inclusion in All Graduate Theses and Dissertations by an authorized administrator of DigitalCommons@USU. For more information, please contact digitalcommons@usu.edu.

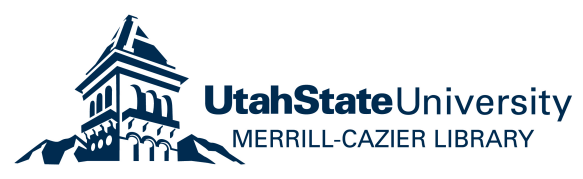


IDENTIFICATION OF PRODUCTS ARISING FROM THE METABOLISM OF CIS- AND TRANS-CHLORDANE BY RAT LIVER MICROSOMES IN VITRO: OUTLINE OF A POSSIBLE METABOLIC PATHWAY

by

Alan Arthur Brimfield

A thesis submitted in partial fulfillment of the requirements for the degree

of

MASTER OF SCIENCE

in

Toxicology

UTAH STATE UNIVERSITY

Logan, Utah

1977 


\section{ACKNOWLEDGEMENTS}

My thanks are due to Professor Joseph C. Street for time, patience and support, both moral and monetary, in the conception and execution of this work and to my wife, Renée, for her support and impatience in seeing that it was completed correctly.

I would also like to acknowledge the kind help and advice of Stephen D. and Gretchen Schramm Wilson in preparation of the manuscript and the graphics.

Alan A. Brimfield 


\section{NOTE OF EXPLANATION}

With the exception of the Appendix, this thesis is set down in the form required for publication in the journal Pesticide Biochemistry and Physiology. The manuscript has been submitted to the journal for publication. 
TABLE OF CONTENTS

Page

ACKNOWLEDGEMENTS . . . . . . . . . ii

NOTE OF EXPLANATION . . . . . . . . . iii

LIST OF FIGURES . . . . . . . . . . . . v v

LIST OF TABLES . . . . . . . . . . . . vi vi

ABSTRACT . . . . . . . . . . . . vii

INTRODUCTION . . . . . . . . . . . . I 1

PROCEDURE . . . . . . . . . . . . 3

RESULTS ................ . . 7

Cis-chlordane . . . . . . . . . . 7

Trans-chlordane . . . . . . . . . 11

DISCUSSION . . . . . . . . . . 15

REFERENCES . . . . . . . . . . . 24

APPENDIX . . . . . . . . . . . 27 


\section{LIST OF FIGURES}

Figure

Page

1. Known or proposed structures for the chlordane isomers and their metabolites identified in this work: 1. cis-chlordane 2. trans-chlordane 3. oxychlordane 4. dichlorochlordene 7. heptachlor 8. 1-chloro-2-hydroxychlordene chlorohydrin 9. dihydroheptachlor. . . . . . .

2. The proposed routes of metabolism of cis- and trans-chlordane in microsomal preparations from induced rat liver. Structure (1-2) represents the complete cis- and trans-chlordane molecules. Metabolites are shown only as the five-membered ring portion of the molecule with the presence of the hexachloronorbornene nucleus understood. Metabolites proposed, but not actually found in this or other work, are designated with a question mark (?) . . . . . . . . . . .

3. The electron impact mass spectrum of the chlordanes . . . . . . . . . . .

4. The electron impact mass spectrum of oxychlordane . . . . . . . . . .

5. The electron impact mass spectrum of dichlorochlordene . . . . . . . . . .

6. The electron impact mass spectrum of chlordene chlorohydrin. . . . . . . . .

7. The electron impact mass spectrum of hydroxychlordene . . . . . . . . . .

8. The electron impact mass spectrum of hydroxychlordane .. . . . . . . .

9. The electron impact mass spectrum of dihydroheptachlor . . . . . . . . .

10. The electron impact mass spectrum of heptachlor

11. The electron impact mass spectrum of the dihydrodiol of heptachlor . . . . . . . . 
1A. Compounds in eluates from column chromatog raphy of an extract from the in vitro metabolism of cis-chlordane. . . . . .

1B. Compounds in eluates from column chromatog raphy of an extract from the in vitro metabolism of trans-chlordane......

2. Detailed mass spectral data for compounds previously unreported as metabolites of chlordane or for which mass spectra have not been published ..........

3. Electron capture gas chromatographic identification of 1-chloro-2-hydroxychlordene chlorohydrin and hydroxychlordene in column fractions III from extracts of in vitro cisand trans-chlordane incubates...... 


\section{ABSTRACT}

Identification of Products Arising from the Metabolism of Cis- and Trans-chlordane by Rat Liver Microsomes In Vitro: Outline of a Possible Metabolic Pathway by Alan Arthur Brimfield Utah State University, 1977 Major Professor: Dr. Joseph C. Street Department: Interdepartmental Program in Toxicology

The metabolism of pure cis- and trans-chlordane was studied in vitro. Microsomal preparations from the livers of male rats induced with cis- or trans-chlordane in feed for ten days were used to metabolize the pure compound corresponding to the inducer. Subsequent extraction, column fractionation and combined gas chromatog raphy-mass spectroscopy resulted in the cha racterization of four compounds not previously reported from an in vitro system.

In addition to the substrate, trans-chlordane extracts contained species with the following molecula $r$ weights and empirical formulae: $\mathrm{m} / \mathrm{e} 370, \mathrm{C}_{10} \mathrm{H}_{5} \mathrm{Cl}_{7}$, heptachlor; m/e $352, \mathrm{C}_{10} \mathrm{H}_{6} \mathrm{OCl}_{6}$, a hydroxylated chlordene; and $\mathrm{m} / \mathrm{e} 422, \mathrm{C}_{10} \mathrm{H}_{6} \mathrm{OCl}_{8}$, a hydroxylated chlordane. Dichlorochlordene, oxychlordane and 1-chloro-2-hydroxychlordene chlorohydrin were also present. With the exception of the hydroxychlordane and heptachlor, cis-chlordane extracts contained all of the metabolites found in the trans-incubates. Additionally, a fully saturated compound $\mathrm{m} / \mathrm{e} 372, \mathrm{C}_{10} \mathrm{H}_{7} \mathrm{Cl}_{7}$, a dihydroheptachlor, was present. The 1,2-trans-dihydrodiol of heptachlor 
found in previous in vitro incubates of cis-chlordane was not present in this extract.

This information has been incorporated into a proposed route for the biotransformation of the chlordanes that offers an explanation for the observed differences in the metabolism of cis- and trans-chlordane. The pathway is based on the reductive dechlorination of the chlordanes through dihydroheptachlor to dihydrochlordene. Parallel pathways of hydroxylation, desaturation and epoxide formation arise at each of these species and at chlordane itself. The trans-isomer is predominantly desaturated or hydroxylated while the cis-isomer mainly undergoes dehalogenation. 


\section{INTRODUCTION}

The metabolism of chlordane has been a topic of interest for some time because of the compound's persistence and the subsequent exposure of nontarget organisms to its residues. In vivo studies have shown that experimental animals eliminate pure chlordane isomers as hydroxylated metabolites and conjugates in urine and feces $(1,2)$. However, the use of in vivo techniques is not without drawbacks since such methods superimpose the effects of digestive tract physiology and microbiology on the hepatic metabolism of xenobiotics. This makes primary hepatic metabolism indistinguishable from total in vivo metabolism and causes uncertainty about the origins of transformation products. This problem is avoided by working in vitro.

In vitro work carried out in our laboratory led to the knowledge that the metabolism of cis- and trans-chlordane ${ }^{1}$ by post mitochondrial supernatant from rat liver leads to an epoxide, oxychlordane (3, fig. 1), probably via the oxidized intermediate dichlorochlordene (4, fig. 1) (3). Other work in the same in vitro system showed that ${ }^{14} \mathrm{C}$-trans-chlordane yielded fewer pola $\mathrm{r}$ metabolites than the cis-isomer. 1-chloro-2-hydroxychlordene chlorohydrin (8, fig. 1) was identified as one of the metabolites arising from trans-chlordane in this system (4).

This paper presents the results of combined gas chromatographic-mass spectral studies on extracts on an in vitro chlordane incubation carried out in washed rat liver microsomes. The purpose of this study was to develop a gas chromatographic method for

${ }^{1}$ Cis-chlordane; 1-exo, 2-exo, 4, 5, 6, 7, 8, 8-octachloro-3a, 4 7, 7a-tetrahydro-4, 7-methanoindane. Trans-chlordane; 1-exo, 2-endo, 4, 5, 6, 7, 8, 8-octa chloro-3a, 4, 5, 5a-tetrahydro-4, 7methanoindane. 
quantitating the metabolites of chlordane as the foundation for further research into the mode of action of the liver microsomal xenobiotic-metabolizing enzymes on isomers of chlordane. 
PROCEDURE

Male Sprague-Dawley rats were allowed free access to ground laboratory diet containing $100 \mathrm{ppm}$ of pure cis- or trans-chlordane. This was done to induce the liver microsomal enzymes specifically responsible for the metabolism of chlordane. After nine days of feeding and one day of starvation, the animals were killed with ether and the livers were excised and minced with scissors. Homogenization was carried out in cold $1.15 \% \mathrm{KCl}(1: 4 \mathrm{w} / \mathrm{v})$ in a Lourdes homogenizer at $70 \%$ of full power for $1.5 \mathrm{~min}$. Following homogenization, the tissue was centrifuged at $10,000 \mathrm{xg}$ and $4^{\circ} \mathrm{C}$ for $15 \mathrm{~min}$. The supernatent was decanted from the pellet and centrifuged at $85,000 \mathrm{x} g$ for one hour to collect the microsomal fraction (5). Microsomes from this centrifugation were then resuspended in an appropriate volume of fresh diluant and recentrifuged at $85,000 \mathrm{x} g$ for one hour to obtain washed microsomes. The purpose of washing was to remove adhering soluble enzymes and glutithione. Assay for glutathione by the method of Beutler, et al. (6) showed no detectable glutathione present after the washing step.

Incubation was based on the procedure reported in La Du, et al. (7) as modified by Shenkman, et al. (8). Six hundred twenty-five ug of the chlordane isomer corresponding to the compound used as an inducer were added to a $25 \mathrm{ml}$ incubation flask in acetone $(50 \mathrm{ul}$ at 12.5 $\mathrm{ug} / \mathrm{ul}$ ). The acetone was driven off with $\mathrm{N}_{2}$ and $0.2 \mathrm{ml}$ of ethyl cellosolve and a large glass bead were added. Final incubation volume was $4.5 \mathrm{ml}$ per flask. This consisted of $0.5 \mathrm{ml}$ of $0.07 \mathrm{M}$ glucose-6phosphate in a $0.24 \mathrm{M} \mathrm{Mg} \mathrm{SO}_{4}$ solution, $0.5 \mathrm{ml}$ of $0.1 \mathrm{M}$ potassium phosphate buffer at $\mathrm{pH} 7.4$ containing 2 units of glucose-6-phosphate dehydrogenase and $1.5 \mathrm{ml}$ of the phosphate buffer containing NADP, $3.67 \mathrm{mM}$. The volume was adjusted to $3.5 \mathrm{ml}$ by adding $0.8 \mathrm{ml}$ of buffer and the flasks, so charged, were placed in a metabolic shaking incubator at $37^{\circ} \mathrm{C}$ with $\mathrm{O}_{2}$ gassing for $5 \mathrm{~min}$. At the end of this 
period the incubation was started by adding $1.0 \mathrm{ml}$ of the microsomal preparation to each flask. Incubation was for 0.5 hours and was terminated by the addition of $10 \mathrm{ml}$ of hexane:isopropyl alcohol $(3: 2 \mathrm{v} / \mathrm{v})$ to each flask. A typical run for the purpose of metabolite recovery consisted of 144 flasks.

After termination of the incubation, the contents of the flasks were pooled and extracted with diethyl ether containing $1.5 \%$ isoamyl alcohol. After sodium sulfate drying and volume reduction, the extracts were taken to dryness over low steam under a stream of dry nitrogen and immediately taken up in $10 \mathrm{ml}$ of petroleum ether $\mathrm{bp} 30$ $60^{\circ} \mathrm{C}$.

A dry bed column (12 mm I. D., glass) containing $10 \mathrm{~g}$ of neutral alumina deactivated by the addition of water $(10 \%, \mathrm{v} / \mathrm{w})$ was prepared and washed with several void volumes of diethyl ether:methanol (9:1, v/v) followed by petroleum ether. The $10 \mathrm{ml}$ petroleum ether extract was added at this point and the column was eluted with petroleum ether followed by diethyl ether:methanol (9:1, v/v). Seven $25 \mathrm{ml}$ fractions were collected. Portions of these were diluted for electron capture gas chromatography and concentrated for combined gas chromatography-mass spectroscopy.

Gas chromatography was performed on a Microtec MT 220 gas chromatog raph with temperature programming capability (Tracor, Inc., Austin, Tx.). The column used was a $55 \mathrm{~cm} \mathrm{x} 0.2 \mathrm{~cm} \mathrm{I}$. D. glass column containing 5\% OV 101 (Applied Science Laboratories, State College, Pa.) on silanized, acid washed Anakrom ABS (Analabs, Inc., North Haven, Ct. ) 80/90 mesh. Nitrogen carrier gas flow was maintained at $21 \mathrm{ml} / \mathrm{min}$. with an inlet pressure of $40 \mathrm{psi}$. The electron capture detector purge gas flow rate was $60 \mathrm{ml} / \mathrm{min}$. The inlet temperature was $250^{\circ} \mathrm{C}$ and the detector temperature was $300^{\circ} \mathrm{C}$. The use of high purity solvents especially prepared for gas chromatog- 
raphy allowed the use of temperature programming with the electron capture detector.

Silylation of column eluates and standard compounds, when necessary, was performed with Sil Prep (Applied Science Laboratories, State College, Pa.). All glass conditions were maintained throughout the procedure. Test tubes were washed with soap and water followed by acetone and dried under a stream of nitrogen. One-half milliliter of the silylation reagent was added to the tubes, shaken and discarded. The tubes were then rinsed with hexane followed by the addition of 250 ul of the alumina column eluate or a standard solution of the compound of interest. This was dried under a stream of nitrogen and $1.0 \mathrm{ml}$ of Sil Prep was added. The tubes were stoppered, shaken and allowed to incubate at room temperature. After $30 \mathrm{~min}$. the contents were diluted with gas chromatographic grade cyclohexane and injected. Solvent blanks, run with each silylation, showed no significant electron capturing peaks.

Gas chromatography-mass spectroscopy was performed on a Hewlett-Packard 5982 quadrapole mass spectrometer equipped with a $2100 \mathrm{~S}$ Microprogrammable Systems Computer, data handling software and a Hewlett-Packard 5710 A gas chromatographic inlet (Hewlett-Packard Corporation, Palo Alto, Ca.). The column used was a $53 \mathrm{~cm} \times 0.2 \mathrm{~cm} \mathrm{I.} \mathrm{D.} \mathrm{glass} \mathrm{column} \mathrm{packed} \mathrm{with} 5 \%$ OV 101 plus $0.2 \%$ Carbowax 20M on Chromosorb W 100/120 mesh (HewlettPackard Corporation, Palo Alto, Ca.). Helium carrier gas flow was $35 \mathrm{ml} / \mathrm{min}$. The injector temperature was held at $200^{\circ} \mathrm{C}$. Analysis was carried out isothermally at $170^{\circ} \mathrm{C}$ for $4 \mathrm{~min}$. and then programmed from $170^{\circ}$ to $230^{\circ} \mathrm{C}$ at $8^{\circ} \mathrm{C} / \mathrm{min}$. The elapsed time of analysis varied from 5 to $25 \mathrm{~min}$, depending on the sample. A glass jet separator joined the gas chromatographic inlet to the mass spectrometer. The pressure across the separator was maintained at 
0.8 torr. The mass spectrometer was run in the electron impact mode at $70 \mathrm{ev}$. with the source temperature at $160^{\circ} \mathrm{C}$ and an ion source pressure of $3 \times 10^{-6}$ torr. 


\section{RESULTS}

The combined gas chromatographic-mass spectral studies were performed on the $25 \mathrm{ml}$ fractions collected from neutral alumina column chromatography. These fractions provide the framework for the presentation of the results of these studies. Tentative identification of all compounds identified by combined gas chromatography-mass spectroscopy is given in Table 1. Detailed mass spectral data for compounds that are previously unreported as chlordane metabolites or for which no spectra have been published are given in Table $2 .^{2}$ Known or proposed structures for the molecules under discussion are presented in Figure 1.

Cis-Chlordane

Fraction I (petroleum ether) from the column chromatography of the cis-chlordane extract contained the bulk of the unmetabolized cischlordane (1, fig. 1), dichlorochlordene (4, fig. 1) and a compound that had a retention time slightly less than that of cis-chlordane on the OV 101 gas chromatographic column. This third compound gave a mass spectrum consistant with a saturated methanoindene de rivative containing seven chlorines. Detailed analysis of the mass spectrum of this compound led us to conclude that it was one of the dihydroheptachlors (9, fig. 1).

None of the epoxide metabolite, oxychlordane (3, fig. 1), was apparent in this fraction during gas chromatography-mass spectroscopy, but reanalysis using the more sensitive electron capture gas chromatography confirmed its presence in low concentration.

\footnotetext{
${ }^{2}$ Detailed mass spectra of heptachlor and the chlordanes can be found in reference 9. Tabulated mass spectral data for oxychlordane has been published in reference 10 . The mass spectrum of 1-hydroxychlordene can be found in reference 11 . Corrected mass spectra for all compounds reported here are presented in the Appendix p. 27.
} 
Table 1A. Compounds in Eluates from Column Chromatography of an Extract from the In Vitro Metabolism of Cis-Chlordane.a

\begin{tabular}{|c|c|c|c|c|}
\hline Compound & $\begin{array}{l}\text { Empirical } \\
\text { Formula } \\
\end{array}$ & $\begin{array}{c}\text { Molecula } r \\
\text { Weight } \\
\end{array}$ & $\begin{array}{l}\text { GLC Retention } \\
\text { Time (min.) }\end{array}$ & $\begin{array}{c}\begin{array}{c}\text { Column Fraction } \\
25 \mathrm{ml}\end{array} \\
\end{array}$ \\
\hline 1. Cis-chlordane & $\mathrm{C}_{10} \mathrm{H}_{6} \mathrm{Cl}_{8}$ & 406 & 2.7 & All \\
\hline 2. Dichlorochlordene & $\mathrm{C}_{10} \mathrm{H}_{4} \mathrm{Cl}_{8}$ & 404 & 1.8 & I \\
\hline 3. Oxychlordane & $\mathrm{C}_{10} \mathrm{H}_{4} \mathrm{OCl}_{8}$ & 420 & 2.1 & I \\
\hline 4. Dihydroheptachlor & $\mathrm{C}_{10} \mathrm{H}_{7} \mathrm{Cl}_{7}$ & 372 & 2.3 & I \\
\hline 5. Hydroxychlordene & $\mathrm{C}_{10} \mathrm{H}_{6} \mathrm{OCl}_{6}$ & 352 & 2. 0 & III \\
\hline 6. Chlordene chlorohydrin & $\mathrm{C}_{10} \mathrm{H}_{7} \mathrm{OCl}_{7}$ & 388 & 3.5 & III \\
\hline
\end{tabular}

Table 1B. Compounds in Eluates from Column Chromatography of an Extract from the In Vitro Metabolism of Trans-Chlordane. a

\begin{tabular}{lllll}
\hline 1. Trans-chlordane & $\mathrm{C}_{10} \mathrm{H}_{6} \mathrm{Cl}_{8}$ & 406 & 2.5 & All \\
2. Dichlorochlordene & $\mathrm{C}_{10} \mathrm{H}_{4} \mathrm{Cl}_{8}$ & 404 & 1.8 & I, II \\
3. Oxychlordane & $\mathrm{C}_{10} \mathrm{H}_{4} \mathrm{OCl}_{8}$ & 420 & 2.1 & I, II \\
4. Heptachlor & $\mathrm{C}_{10} \mathrm{H}_{5} \mathrm{Cl}_{7}$ & 370 & 1.3 & III \\
5. Chlordene Chlorohydrin & $\mathrm{C}_{10} \mathrm{H}_{7} \mathrm{OCl}_{7}$ & 388 & 3.5 & III \\
6. Hydroxychlordene & $\mathrm{C}_{10} \mathrm{H}_{6} \mathrm{OCl}_{6}$ & 352 & 2.0 & III \\
7. Hydroxychlordans & $\mathrm{C}_{10} \mathrm{H}_{6} \mathrm{OCl}_{8}$ & 422 & 4.8 & III \\
\hline
\end{tabular}

${ }^{a}$ Gas chromatographic conditions outlined in the text. 
Table 2. Detailed mass spectral data for compounds previously unreported as metabolites of chlordane or for which mass spectra have not been published.a

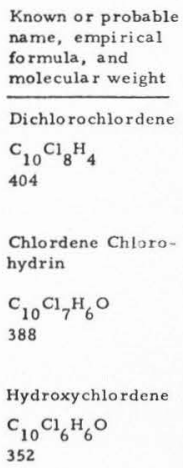

$\mathrm{C}_{10} \mathrm{Cl}_{8} \mathrm{H}_{6} \mathrm{O}$

422

Dihydroheptachlor

$\mathrm{C}_{10} \mathrm{Cl}_{7} \mathrm{H}_{7}$

372

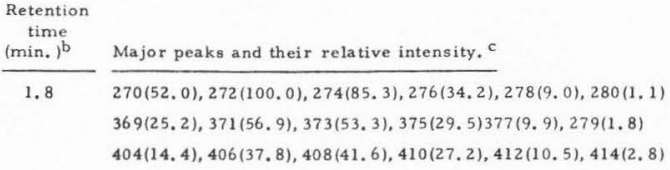

2. 0

$270(11,3), 272(21,6), 274(16,5), 276(8,7), 278(2,4)$

$281(33.5), 283(38.7), 285(18.2), 287(4.6)$

$316(27,5), 318(48,2), 320(41,4), 322(15,3), 324(2.6)$

$317(48.1), 319(100,0), 321(62.0), 323(21.1), 325(3.8)$

No Parent Ion

4. $8 \quad 387(42.8), 389(100.0), 391(92.4), 393(45.7), 395(17.3), 397(3.5)$ $422(4.6), 424(10.0), 426(11.1), 428(4.4)$

2. $3 \quad 337(45.8), 339(100.0), 341(77.2), 343(39.3), 345(8.9)$ $372(5.9), 374(10.7), 376(9.5), 378(3.2), 380(1.8)$

${ }^{a}$ Corrected mass spectra for all compounds reported here are presented in the Appendix p. 27.

bGas chromatographic conditions outlined in text.

"Statistical considerations in data collection forced us to scan only from 250-440 amu, so these spectra are not complete. Relative percent abundancies for the 250-440 amu scan are given in parenthesis. 

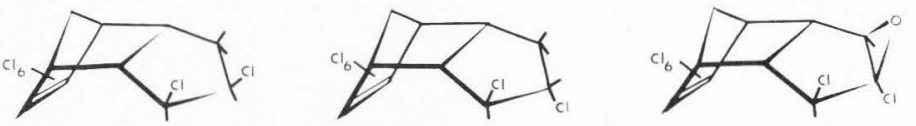

2
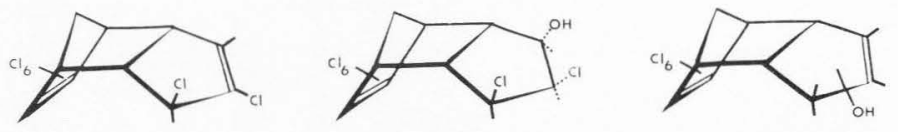

6
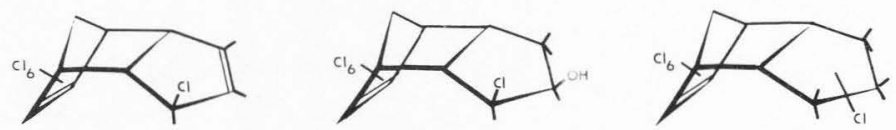

8

Figure 1. Known or proposed structures for the chlordane isomers and their metabolites identified in this work: 1. cis-chlordane 2. trans-chlordane 3. oxychlorodane 4. dichlorochlordene 5. hydroxychlordane 6. hydroxychlordene 7. heptachlor 8. 1-chloro-2-hydroxychlordene chlorohydrin 9. dihydroheptachlor. 
Fraction II (petroleum ether) contained cis-chlordane and a slight quantity of dichlorochlordene.

Fraction III (mixed; petroleum ether, diethyl ether-methanol 9:1 v/v) again showed the presence of parent cis-chlordane. The 1-chloro-2-hydroxychlordene chlorohydrin (8, fig. 1) was also present in this fraction. Its positive identification was based on comparison of its gas chromatographic retention time and mass spectrum with that of a known standard. Silylation and rechromatography on gas chromatography confirmed this (Table 3). A third compound, which failed to show up on gas chromatography-mass spectroscopy, appeared in the electron capture gas chromatography. That peak corresponded in retention time to hydroxychlordene. Its identity was confirmed by comparison of its gas chromatographic retention time with that of a standard compound both before and after silylation (Table 3).

Combined gas chromatography-mass spectroscopy of column fractions IV through VII only showed the presence of increasingly smaller quantities of cis-chlordane. Combination of the four fractions and volume reduction to $1 \mathrm{ml}$ still showed the presence of no peaks other than cis-chlordane. Mass spectra at significant retention times and specific ion monitoring yielded no additional information. It is noteworthy that no evidence of the 1,2-trans-dihydrodiol of heptachlor was found by any technique in these extracts. This compound has been detected by gas chromatography-mass spectroscopy in column fractions from extracts of cis-chlordane incubates in previous work using our in vitro system, but not consistently (12).

Trans-Chlordane

Column fractions from the extract of the trans-chlordane incubates showed a pattern similar to the cis-fractions when subjected to combined gas chromatography-mass spectroscopy. Fraction I (petroleum ether) contained unmetabolized trans-chlordane (2, fig. 1), 
Table 3. EC-GLC ${ }^{a}$ Identification of 1-Chloro-2-hydroxychlordene Chlorohydrin and Hydroxychlordene in Column Fractions III from Extracts of In Vitro Cis-and Trans-Chlordane Incubations.

Reference Standards

Trans-Chlordane

Cis-Chlordane

Hydroxychlordene

1-Chloro-2-hydroxychlordene

Chlorohydrin

Cis-Chlordane Extract

Column Fraction III

Peak A

Peak B

Peak C

Trans-Chlordane Extract

Column Fraction III

Peak A

Peak B

Peak C
Retention Time Before Silanization (min.)

\subsection{5}

5.80

3.75

6.30
Retention Time After Silanization (min.)

5.25

5.80

4. 10

3. 75

4. 10

5. 80

5. 80

6.30

7. 60
3. 75

5.25

6.30
4. 10

5.25

7.60

${ }^{a}$ Column, $158 \times 0.2 \mathrm{~cm}$ glass packed with $5.0 \%$ OV-101 $+0.5 \%$ Carbowax on silanized acid wa shed Anakrom $80 / 90$ mesh; column temperature, $195^{\circ} \mathrm{C}$ isothermal; inlet temperature, $235^{\circ} \mathrm{C}$; electron capture detector temperature $305^{\circ} \mathrm{C}$; carrier gas flow rate $42 \mathrm{ml} / \mathrm{min}$. $\mathrm{N}_{2}$; AFS $64 \times 10^{-11} \mathrm{amps}$. 
oxychlordane and dichlorochlordene. A small quantity of material having the same molecular ion and mass spectrum as heptachlor (7, fig. 1) was present in this fraction. This was first assumed to represent a contaminant in the trans-chlordane that was used as substrate for the in vitro microsomal system. Re-examination of the substrate did show the presence of a small amount of heptachlor contamination (308 ppm). However, quantitation and comparison of quantities of chlordane and known chlordane-derived material to heptachlor in all seven column fractions gave a ratio of 175:1 (chlordane plus chlordane-derived material:heptachlor). The ratio of trans-chlordane to heptachlor in the substrate was 3,250:1. It is concluded that heptachlor, or a compound very similar to it, is a metabolite of trans-chlordane, albeit a minor one. Fraction II (petroleum ether) contained trans-chlordane, oxychlordane and dichlorochlordene, but no other products.

Fraction III (mixed; petroleum ether, diethyl ether-methanol $9: 1, \mathrm{v} / \mathrm{v})$ proved to be the one of greatest interest obtained from the trans-chlordane extract. It contained the parent compound plus material giving six other gas chromatographic peaks on the total ion current monitor. The first of these eluted from the gas chromatograph before trans-chlordane. Comparison of its mass spectrum with a published spectrum of hydroxychlordene (6, fig. 1) (11) showed excellent correlation in every respect except for the molecula $\mathrm{r}$ ion peak which did not appear in our mass spectrum (see Table 2). A second peak, eluting after trans-chlordane, proved to be 1-chloro-2-hydroxychlordene chlorohydrin (also observed in Fraction III of the cis-chlordane extract and confirmed by comparison of mass spectra and retention times with those from the cisextract). A third compound eluted from the gas chromatograph after the chlorohydrin. It had a molecula $\mathrm{r}$ ion of $\mathrm{m} / \mathrm{e} 422$, consistent with an empirical formula of $\mathrm{C}_{10} \mathrm{Cl}_{8} \mathrm{H}_{6} \mathrm{O}$ (Table 2). This was 
interpreted as a hydroxylated chlordane. The remaining three minor peaks had greater retention times than the hydroxychlordane, but were not present in sufficient quantity to yield usable mass spectra, even after the application of computer averaging. As in the case of the cis-chlordane extract, analysis of the four remaining column fractions provided no additional information. 


\section{DISCUSSION}

This work was originally undertaken to develop a gas chromatographic quantitation procedure for the metabolites of cis- and trans-chlordane. Combined gas chromatography-mass spectroscopy is a powerful tool in such a process. In most cases it allows the investigator to identify the components of a mixture resolved by gas chromatography to the point of arriving at a molecular weight and, ultimately, an empirical formula. In the case of halogenated compounds such as chlordane, one has the added advantage of using theoretical isotope distributions to determine the exact number of halogen atoms present on a given component of a mixture. When the history of such a mixture is known, as in the case of the metabolites of a well characterized starting material, the only remaining ambiguity is the specific stereochemical configuration of the components. Even this uncertainty yields, to some extent, when fragmentation patterns for a series of known cogeners can be compared and analyzed.

Previous studies of the electron impact mass spectral behavior of the methanoindene derivatives have shown that the main modes of fragmentation of these compounds are the loss of $\mathrm{HCl}$ and $\mathrm{Cl}$ and retro-Diels-Alder collapse of the carbon skeleton $(9,11)$. Surprisingly, loss of oxygen and oxygen containing fragments, other than in the retro-Diels-Alder decompositions, plays a relatively minor role in the fragmentation of the epoxides and hydroxylated metabolites (11).

Due to the limitations in the rate at which spectra could be recorded on the instrument used in this study and the small quantities of material analyzed, the window width had to be limited to 200 amu (vis., 250-450 amu) to provide statistically useful spectra. For this reason metabolite identification was based on the parent ion when it was present, and those fragments that arose from the loss of $\mathrm{Cl}$ and $\mathrm{HCl}$ plus combinations of these: $\mathrm{P}-\mathrm{Cl}-\mathrm{HCl}$ and $\mathrm{P}-\mathrm{Cl}_{2}$. The only 
retro-Diels-Alder fragment that was consistently found within the 200 amu window was hexachlorocyclopentadiene at $\mathrm{m} / \mathrm{e} 270$. Most of the fragments that result from retro-Diels-Alder collapse are in the mass range from 70 to $250 \mathrm{amu}$ (9). Since these a re the fragments that allow conclusions to be drawn about configuration, this was not possible with our data. Fortunately, the information found in the upper $200 \mathrm{amu}$ of the mass spectrum was sufficient for metabolite identification.

Our long term goal is, and has been, to explain the divergence in the hepatic metabolism of cis-and trans-chlordane in the rat. This divergence manifests itself in vitro as the production of a larger quantity of oxychlordane from trans-chlordane than from the cisisomer (13) and correspondingly more protein-bound material and hydrophilic metabolites from cis- than from trans- $(4,12)$. The results of the present study have been doubly helpful in explaining this phenomenon. Based on the combined gas chromatography-mass spectroscopy work, we are now well along toward a gas chromatographic quantitation procedure for the metabolites of the chlordanes. Additionally, we have formulated a working hypothesis to explain the observed divergence in chlordane biotransformation.

This hypothesis is in the form of a proposed pathway for chlordane metabolism and is based on a rational synthesis of our results and the results of those who have studied cyclodiene metabolism in the past (figure 2). As the figure shows, a molecule of chlordane can follow one of three courses during hepatic microsomal metabolism. It is either immediately hydroxylated at the three position to give hydroxychlordane $(3$, fig. 2$)$, desaturated to dichlorochlordene $(4$, fig. 2$)$ prior to epoxidation, or it proceeds through reductive dehalogenations to give dihydroheptachlor and dihydrochlordene ( 6 and 11, fig. 2). The dehalogenated molecules can then participate in the pathways of hydroxylation, or desaturation and 


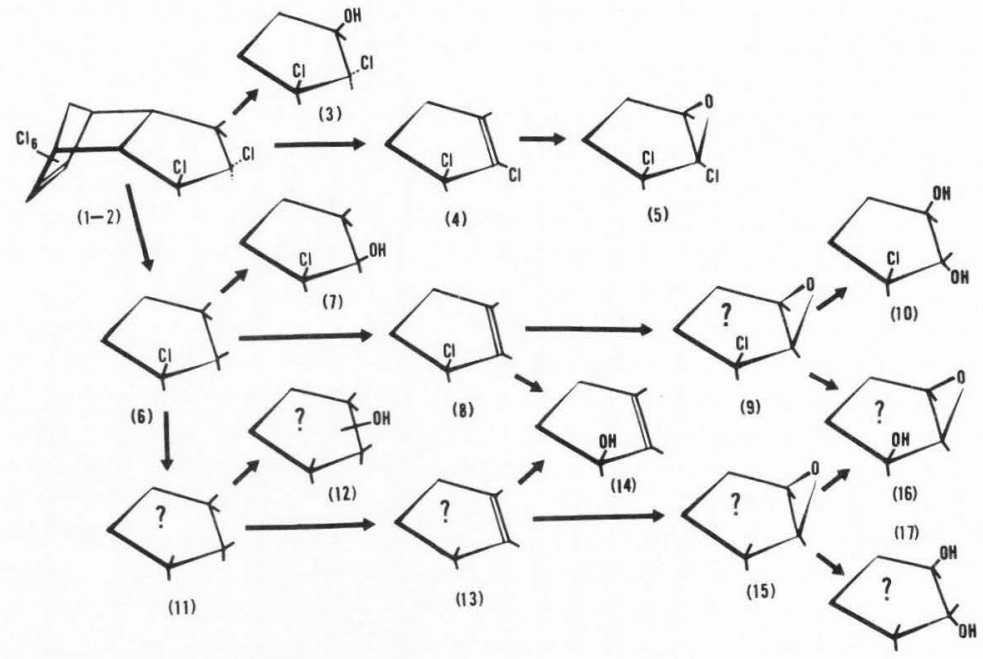

Figure 2. The proposed routes of metabolism of cis-and trans-chlordane in microsomal preparations from induced rat liver. Structure (1-2) represents the complete cis- and trans-chlordane molecules. Metabolites a re shown only as the five-membered ring portion of the molecule with the hexachloronorbornene nucleus understood. Metabolites proposed, but not actually found in this or other work, are designated with a question mark (?). 
epoxidation, or both that parallel the formation of dichlorochlordene and oxychlordane from chlordane. Presumably, the major route taken by a given chlordane isomer is determined by whether the chlorine at position 2 is exo (cis) or endo (trans). The transisomer is predominantly desaturated or hydroxylated while the cisisomer is dehalogenated as its major mode of biotransformation. Ignoring the cis-trans isomerism for a moment, the chlordanes as an entity pose a unique situation among the insecticides of the cyclodiene family. The chlordanes, along with nonachlor, the dihydroheptachlors and dihydrochlordene, are the only members of the family that present a fully reduced structure to the hepatic xenobiotic metabolizing enzymes. The other commonly encountered members of this group such as heptachlor, aldrin, heptachlor epoxide and dieldrin contain either a double bond or an epoxidized double bond in addition to the double bond found universally in the hexachloronorbornene nucleus. As a result of this saturation, the hepatic metabolism of the chlordanes requires an additional step: the insertion of a double bond. Street and Blau (3) recognized this and proposed that the desaturation was the rate limiting step in oxychlordane production in the rat.

The effect of the absence of the double bond in the metabolism of the methanonaphthalene derivatives, aldrin and 6,7-dihydroaldrin, was investigated by Brooks (14). He subjected these compounds to metabolism by pig liver microsomes in the presence of $\mathrm{NADPH}_{2}$ and oxygen and found that, in the absence of the double bond, dihydroaldrin was hydroxylated at the 6 position. Aldrin, on the other hand, was oxidized to its epoxide metabolite, dieldrin. Other work allows the same comparison between the methanoindene derivatives heptachlor and dihydroheptachlor. The majority of heptachlor fed to rats and rabbits was isolated from the fat, organs, urine and feces as an epoxide (15). But, when the metabolism of alpha-dihydroheptachlor 
in pig liver microsomes was investigated, mostly hydroxylated metabolites were produced (16). It seems clear, based on this information, that the oxidation state of cyclodienes, external to the hexachloronorbornene nucleus, has a profound effect on their mode of metabolism. That is, double bonds become epoxidized while the corresponding saturated sites a re hydroxylated.

Two additional paths, desaturation and dehalogenation, compete with epoxidation and hydroxylation for the fully reduced cyclodienes at various points in their metabolism by mammalian liver. Desaturation is well documented as a mode of metabolism for chlordane, both isomers being transformed to dichlorochlordene (3). But the products of the desaturation of the less highly chlorinated methanoindene derivatives, the dihydroheptachlors and dihydrochlordene, have not been reported.

Nevertheless, evidence of such metabolites does exist. A desaturated metabolite was isolated and identified from the in vitro biotransformation of gamma-dihydroheptachlor in pig liver microsomes (16). The metabolite, 3-hydroxychlordene, was of interest at the time because it was hydroxylated, but it also contained a double bond. None of the metabolites identified in incubates from alpha- and betadihydroheptachlor, investigated in the same study, was desaturated, but in each case chlorinated hydrocarbons were produced that chromatographed with the parent compound and were not identified. Any desaturated non-oxygen containing compound would have fallen into this uninvestigated group, for the non-hydroxylated, non-epoxidized, desaturated metabolites of the saturated methanoindenes are very similar to their saturated parent compounds in polarity and chromatographic behavior. A case in point is the chromatographic behavior of dichlorochlordene with respect to chlordane. These two compounds travel together in many chromatographic systems including the neutral alumina column used in this work. So, the likelihood is that 
desaturation participates, to some extent, in the metabolism of all the saturated methanoindenes.

Dehalogenation, as a discrete mode of metabolism, so far has not been reported for cyclodienes. Heptachlor and the 1-chloro-2hydroxychlordene chlorohydrin found in this work probably arise as the result of dehalogenation reactions followed by an additional mode of biotransformation such as hydroxylation or desaturation. The literature abounds with other examples of dehalogenated metabolites arising from just such a sequence of metabolic transformations (15, 16, 17). The difficulty, until now, seems to have been in finding dehalogenated metabolites that had not been otherwise metabolized prior to isolation. The identification of a small quantity of a dihydrohepta chlor from the in vitro metabolism of cis-chlordane strongly suggests that dehalogenation participates in the biotransformation of the reduced cyclodienes in and of itself and not as a concerted step that occurs with hydroxylation or desaturation. This suggestion is not an entirely novel one. It has been known for some time, for example, that DDT is converted to its reduced dehalogenated metabolite DDD in liver in vivo (18), and in vitro $(19,20)$. The $\mathrm{NADPH}_{2}, \mathrm{O}_{2}$ dependent reductive dehalogenation of 1,1,2-trichloroethane has been described (21).

The final mode of cyclodiene metabolism that should be considered is the hydrolytic cleavage of epoxides. This reaction involves the rupture of the oxirane ring of cyclodiene epoxides by the microsomal enzyme hepatic epoxide hydratase (dihydrodiol hydro-lyase (a rene-oxide-forming), E. C. 4.2.1.64) (22). The reaction is stereospecific, always yielding trans-dihydrodiols, and is independent of molecular oxygen and $\mathrm{NADPH}_{2}(23,24)$. No evidence has been found to indicate an interaction of this enzyme with oxychlordane despite attempts to show such an interaction, but the cleavage of heptachlor epoxide, the epoxide of chlordene and epoxides of various methano- 
naphthalene derivatives is well documented (24). It is possible that the endo-chlorine on carbon number 2 of oxychlordane prevents its interaction with epoxide hydratase. Our finding of a dihydrodiol of heptachlor (10, fig. 2) from cis-chlordane as well as the report of a six chlorine containing diol from an in vivo study of chlordane metabolism (1) provides evidence that epoxide hydratase is involved in chlordane metabolism via the epoxides of heptachlor and chlordene.

Epoxidation, hydroxylation, desaturation and epoxide cleavage are well established routes of cyclodiene metabolism. In the light of the identification of a dihydroheptachlor reported here, discrete dehalogenation cannot be ignored as a possible additional direction by which biotransformation can proceed. Based on these paths of metabolism and the metabolites reported from this and previous studies of chlordane metabolism, it is possible to rationally construct a complete pathway for chlordane biotransformation in mammalian liver up to the point of conjugation.

Such a pathway is shown in figure 2. The pivotal point in this proposed route is the dehalogenation reaction. As each chlorine is removed, transformation from chlordane (1-2, fig. 2) through dihydroheptachlor (6, fig。2) to dihydrochlordene (11, fig. 2) occurs and a new cycle of desaturation and epoxidation, and hydroxylation begins. Semiquantitative comparison of the amounts of hydroxychlordane (3, fig. 2) produced from chlordane versus the amount of 1-chloro-2hydroxychlordene chlorohydrin (7, fig. 2) produced from dihydroheptachlor indicate that dihydroheptachlor is a more favorable candidate for hydroxylation than chlordane. So, it seems, that as each chlorine is removed by dechlorination another site is open to hydroxylation and this reaction comes to compete more effectively with desaturation for the available reduced substrate. This situation becomes extreme in the case of dihydrochlordene in which the hydroxylated metabolite, hydroxychlordene (14, fig. 2), was found but 
none of the parent compound. In fact, the finding of this hydroxylated, desaturated metabolite may be an indication that, in the case of the completely nonchlorinated five-membered ring, hydroxylation begins to compete successfully with epoxidation for the desaturated substrate as well as for the saturated dihydrochlordene.

Epoxide hydration, apparently, is also dependent on the degree of dehalogenation. This explains the fact that none of the dihydrodiols reported as the result of chlordane metabolism contains more than seven chlorine atoms $(1,12)$. As mentioned above, the endo-chlorine in position 2 on oxychlordane probably prevents its metabolism by epoxide hydratase and leads to its role as the lipid storage form of chlordane. In the epoxides of dihydroheptachlor (9, fig. 2) and dihydrochlordene (15, fig. 2), on the other hand, this position is vulnerable to attack by epoxide hydratase leading to the reported diols (10 and 17, fig. 2) (23, 25).

Similarly, hydroxylation apparently cannot occur in the case of oxychlordane for the same reason: the exo-chlorine atom on position 1 is covering the only "hydroxylatable" position on the five-membered ring. This follows from the fact that no hydroxyepoxide of chlordane has been reported. The epoxide of dihydrochlordene does have a reduced non-chlorine containing site at several positions. As a result of this, hydroxylation is a possible metabolic alternative and a hydroxyepoxide (16, fig. 2) has, indeed, been reported from this compound (15, 24).

In addition to outlining a possible overall route to explain the metabolism of chlordane, the proposed pathway provides a basis for explaining the divergence in the metabolism of cis- and trans-chlordane. One can speculate that the orientation of the chlorine atom on carbon 2 of the chlordane molecule influences the tendency for desaturation (trans) or dechlorination (cis) mechanisms. The suggested pathway presented in figure 2 illustrates this concept. 
Regardless of the intellectual appeal of such a pathway and the circumstantial evidence that can be gathered in its favor, as long as the mechanism of the microsomal mixed function oxidases remains obscure, the origin of these metabolites is a matter of speculation. It is reasonable from the point of view of organic chemistry, for example, to suggest that the chlorohydrin of chlordene (7, fig. 2) a rises directly from cis-chlordane via nucleophilic substitution by water on a carbonium ion intermediate in an $S_{n} 1$ type reaction. It is equally plausible that trans-chlordane could give rise directly to heptachlor (8, fig. 2) by an $E_{2}$ mechanism in which the exo proton in position 3 on the chlordane is abstracted causing the loss of $\mathrm{Cl}^{-}$in a dehydrohalogenation reaction. 


\section{REFERENCES}

1. J. H. Barnett and H. W. Dorough, Metabolism of Chlordane in Rats, J. Agr. Food Chem. 22, 612 (1974).

2. N. H. Poonawalla and F. Korte, Metabolism of trans-Chlordane${ }^{14} \mathrm{C}$ and Isolation and Identification of Its Metabolites from the Urine of Rabbits, J. Agr. Food Chem. 19, 467 (1971).

3. J. C. Street and S. E. Blau, Oxychlordane: Accumulation in Rat Adipose Tissue on Feeding Chlordane Isomers and Technical Chlordane, J. Agr. Food Chem. 20, 395 (1972).

4. A. A. Brimfield and J. C. Street, Comparison of Metabolism of Cis- and Trans-Chlordane In Vitro in Liver Homogenates from the Rat, Paper presented at the 167 th national meeting of the American Chemical Society, Los Angeles, Ca. April 1974.

5. A. Claude, Fractionation of Mammalian Tiver Cells by Differential Centrifugation, J. Exp. Med. 84, 61 (1946).

6. E. Beutler, O. Duron and B. M. Kelly, Improved Method for the Determination of Blood Glutathione, J. Lab. Clin. Med. 61, 882 (1963).

7. B. N. La Du, L. Gaudette, N. Trousof, and B. B. Brodie, Enzymatic Dealkylation of Aminopyrine (Pyramidon) and other Alkylamines, J. Biol. Chem, 214, 741 (1954).

8. J. B. Schenkman, J. A. Ball and R. W. Estabrook, On the Use of Nicotinamide in Assays for Microsomal Mixed Function Oxidase Activity, Biochem. Pharmacol. 16, 1071 (1967).

9. J. N. Damico, R. P. Barron and J. M. Ruth, Mass Spectra of Some Chlorinated Insecticidal Compounds, Org. Mass Spectrom. 1,331 (1968).

10. B. Schwemmer, W. P. Cochrane and P. B. Polen, Oxychlordane, Animal Metabolite of Chlordane: Isolation and Synthesis, Science 169, 1087 (1970).

11. A. Demayo and M. Comba, Gas Chromatographic and Direct Inlets Mass Spectra of Heptachlor and 1-Hydroxychlordene, Bull. Environ. Contam. Toxicol. 8, 212 (1972).

12. A. A. Brimfield and J. C. Street, Unpublished observations. 
13. J. C. Street and S. E. Blau, Chlordane Metabolism in Rat Liver In Vitro, Paper presented at the 16lst national meeting of the American Chemical Society, Los Angeles, Ca. March 1971.

14. G. T. Brooks and A. Harrison, The Oxidative Metabolism of Aldrin and Dihydroaldrin by Houseflies, Housefly Microsomes and Pig Liver Microsomes and the Effect of Inhibitors, Biochem. Pha rmacol. 18, 557 (1969).

15. R. Kaul, W. Klein and F. Korte, Beitrage zur Okologischen Chemie - XX Verteilung, Ausscheidung und Metabolismus von Telodrin und Heptachlor in Ratten und Mannlichen Kaninchen, Endprodukt des Warmblutermetabolismus von Heptachlor, Tetrahedron. 26, 331 (1970).

16. G. T. Brooks and A. Harrison, The Toxicity of Alpha-Dihydroheptachlor and Related Compounds to the Housefly (M. domestica $L_{0}$ ) and Their Metabolism by Housefly and Pig Liver Microsomes, Life Sci. 6, 1439 (1967).

17. R. Kaul, W. Klein and F. Korte, Beitrage zur Okologischen Chemie - XXI Metabolismus und Kinetik der Verteilung von Beta-Dihydroheptachlor- ${ }^{14} \mathrm{C}$ in Mannlichen Ratten, Tetrahedron. 26, 99 (1970).

18. P. R. Datta, E. P. Laug and A. Klein, Conversion of p, p'-DDT to $\mathrm{p}, \mathrm{p}^{\prime}-\mathrm{DDD}$ in the Liver of the Rat, Science 145, 1052 (1964).

19. J. E. Peterson and W. H. Robison, Metabolic Products of p, p'-DDT in the Rat, Toxicol. App. Pharmacol. 6, 321 (1964).

20. P. J. Bunyan, J. M. J. Page and A. Taylor, In Vitro Metabolism of p, p'-DDT in Pigeon Liver, Nature 201, 1048 (1966).

21. R。A. Van Dyke and A. J. Gandolfi, Cha racteristics of a Microsomal Dechlorination System, Mol Pharmacol. 11, 809 (1975).

22. The Commission on Biochemical Nomenclature; International Union of Biochemistry, Enzyme Nomenclature in "Comprehensive Biochemistry" (M. Florkin and E. H. Stotz, Ed.), Vol. 13, p. 294, Elsevier Scientific Publishing Co., New York, 1972. 
23. G. T. Brooks, A. Harrison and S. E. Lewis, Cyclodiene Epoxide Ring Hydration by Microsomes from Mammalian Liver and Houseflies, Biochem. Pharmacol. 19, 225 (1970).

24. G. T. Brooks, Progress in Metabolic Studies of the Cyclodiene Insecticides and its Relevance to Structure-Activity-Correlations, World Rev. of Pest Cont. 5, 62 (1966).

25. G. T. Brooks, S. E. Lewis and A. Harrison, Selective Metabolism of Cyclodiene Insecticide Enantiomers by Pig Liver Microsomal Enzymes, Nature 220, 1034 (1968). 
APPENDIX 
Space considerations in the journal format do not allow the publication of blocks of data such as mass spectra. For the sake of completeness in this thesis, however, drawings of the spectra of the compounds under discussion have been included in this appendix.

These spectra are by no means complete. In addition to the fact that they reflect only those ions found between 250 and 450 amu, only major groupings derived from the compound of interest are shown. In many cases overlapping gas chromatographic peaks caused mixed spectra to be recorded. At other times unknown contaminants contributed to the mass spectra. These types of interfering peaks and peak groupings have been eliminated. All of the spectra shown here were recorded on the Hewlett-Packard 5982 mass spectrometer. 


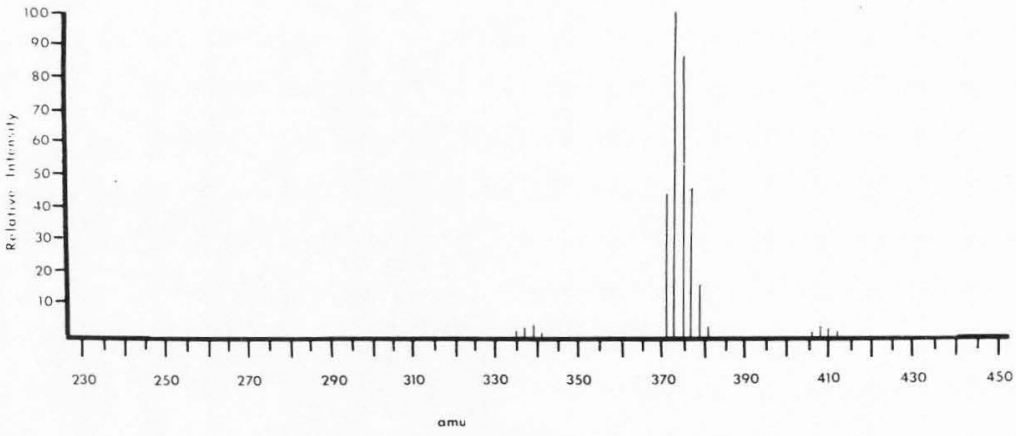

Figure 3. The electron impact mass spectrum of the chlordanes. 


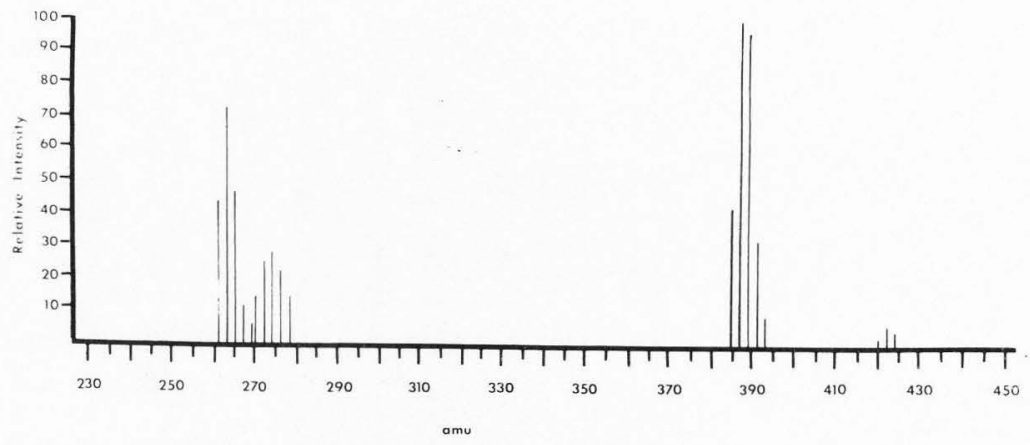

Figure 4. The electron impact mass spectrum of oxychlordane. 


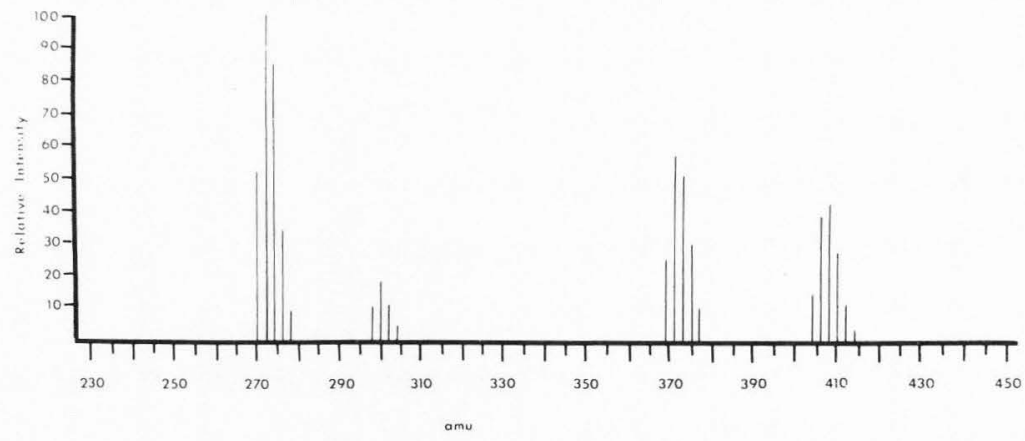

Figure 5. The electron impact mass spectrum of dichlorochlordene. 


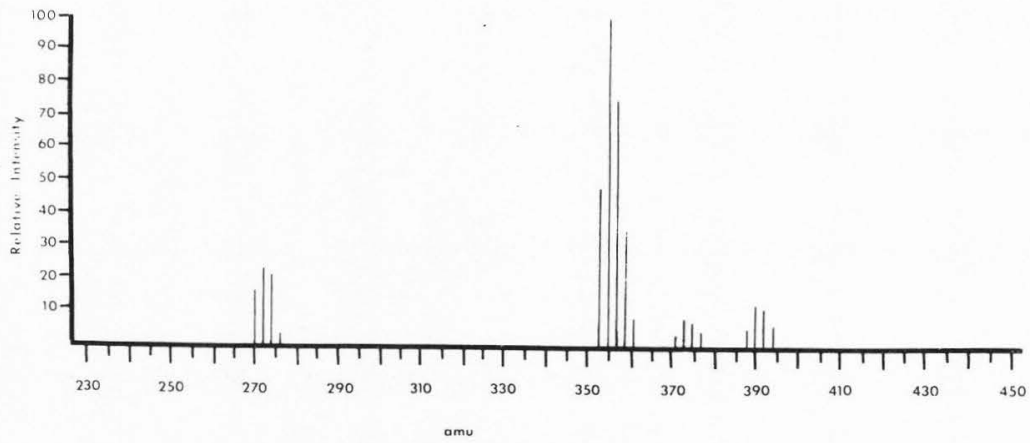

Figure 6. The electron impact mass spectrum of 1-chloro-2-hydroxychlordene chlorohydrin. 


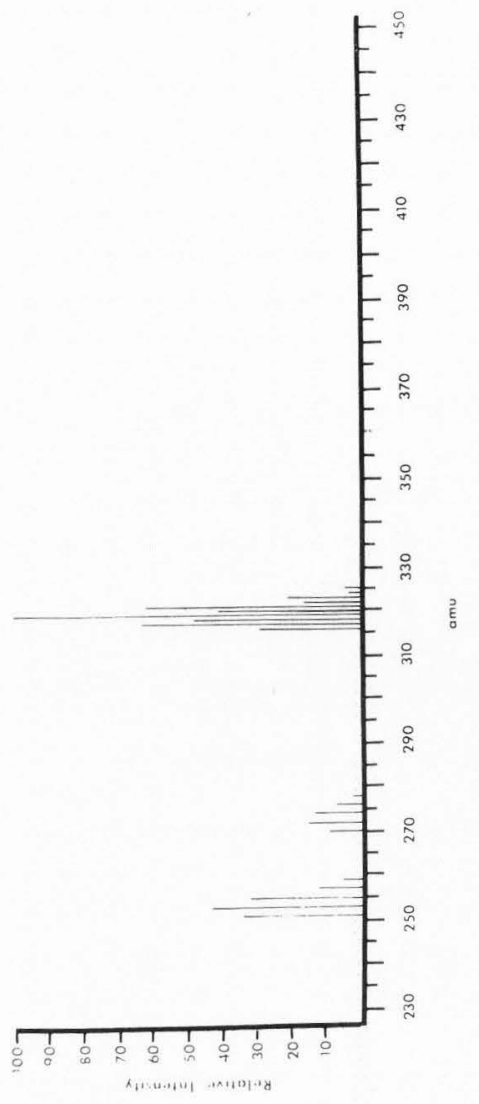

0 


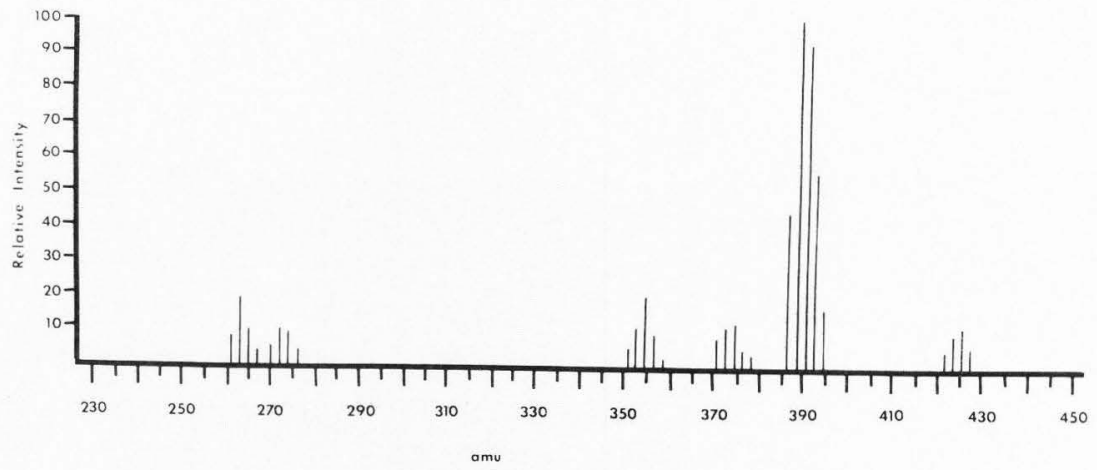

Figure 8. The electron impact mass spectrum of hydroxychlordane. 


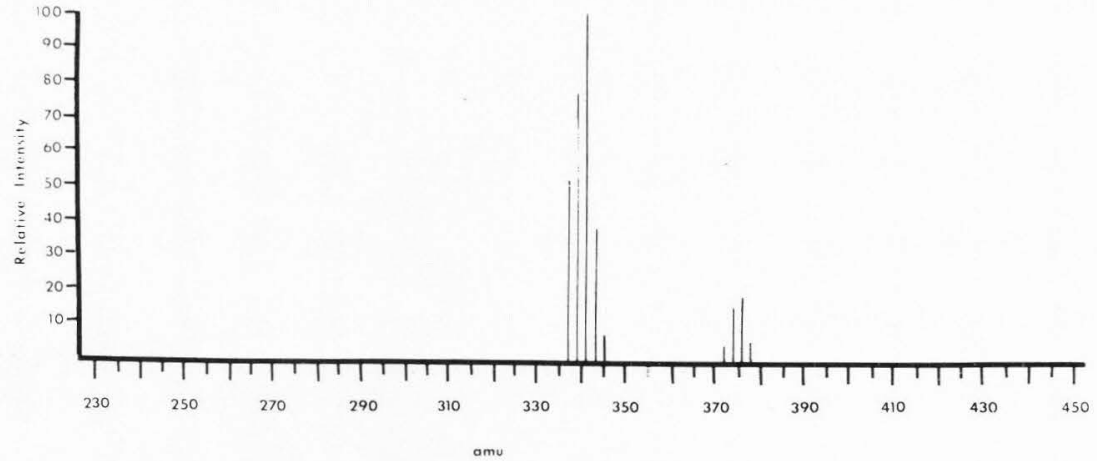

Figure 9. The electron impact mass spectrum of dihydroheptachlor. 


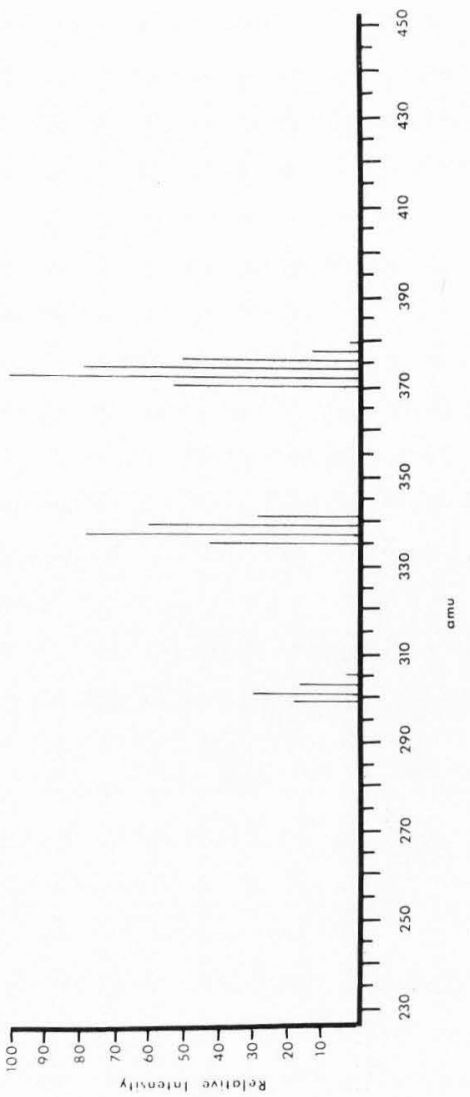

d 


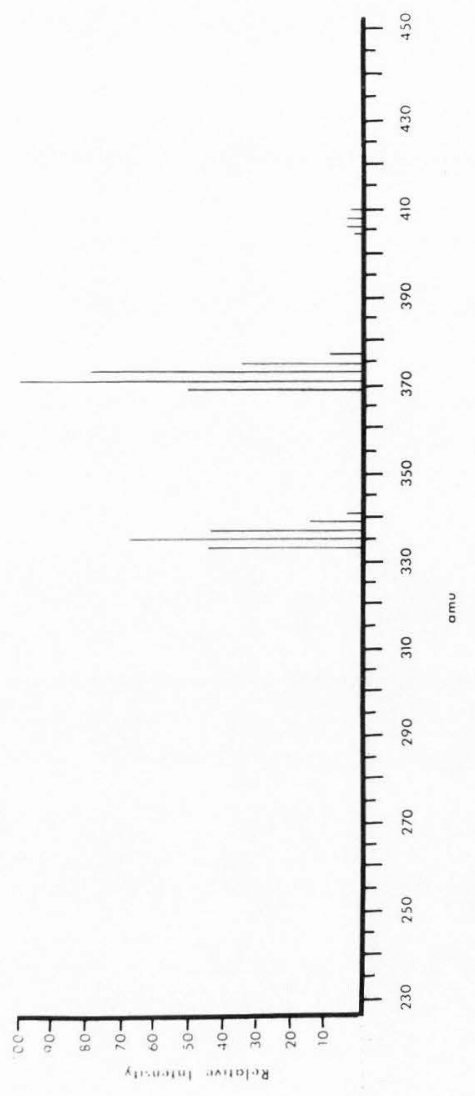

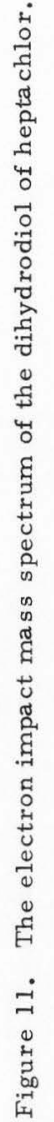

